Profit: Jurnal Kajian Ekonomi dan Perbankan 3 (1) 2019. P: 45-51

PROFIT : JURNAL KAJIAN EKONOMI DAN PERBANKAN

https://ejournal.unuja.ac.id/index.php/profit

E-ISSN : 2597-9434

\title{
ANALISIS PENGARUH FAKTOR KELENGKAPAN PRODUK, KUALITAS PRODUK DAN CITRA PRODUK TERHADAP LOYALITAS KONSUMEN BASMALAH MARKET KARANGGENENG
}

\section{Nurus Safa'atillah *}

* Fakultas Ekonomi

Manajemen Universitas Islam Lamongan

\begin{abstract}
:
The purpose of this study was to determine the complecateness of the product, product quality, and product image effect partially or simultaneously on consumer loyality to the market Basmallah Karanggeneng Lamongan, as well as to determine the complecateness of the product, product quality, and product image, which is more dominant effect on consumer loyality partners market Basmallah Karanggeneng Lamongan. From the results obtained $\mathrm{t}$ test the completeness of the product (3.244), product quality (6.615), and the image of the product (11.217). The independent variable range of product, product quality and product image has $t$ hitung $>\mathrm{t}$ table (1.984) then $\mathrm{H} 0$ rejected and $\mathrm{Ha}$ is received so at it can be interpreted that the independent variable range of products, product quality and product image partially has a significant effect on the dependent variable customer loyality. And the rest results obtained F hitung (94.545), while $\mathrm{F}$ table $(2,70)$ for $\mathrm{F}$ count $>\mathrm{F}$ table then $\mathrm{H} 0$ rejected and $\mathrm{Ha}$ is received so that it can be interpreted that the independent variable range of products, product quality and product image simultaneously have a significant effect on the dependent variable consumer loyality.
\end{abstract}

Keywords: Completenes Products, Products Quality and Image Products and Consumer Loyality.

Email : 


\section{PENDAHULUAN}

\section{A. Latar Belakang}

Perkembangan teknologi dan industri membawa dampak bagi kehidupan manusia terutama dunia usaha pada saat ini. Di samping itu banyaknya usaha yang memunculkan usaha kecil maupun besar berdampak pada persaingan yang ketat antar perusahaan baik yang sejenis maupun yang tidak sejenis. Perubahan zaman juga membuat terjadinya pergesaran nilai-nilai dalam dunia bisnis, saat ini konsumen lebih mempunyai kekuasaan yang menentukan didalam dunia bisnis, oleh karena itu para pemasar juga harus mendalami berbagai pengaruh terhadap pembeli dan mengembangkan pemahaman mengenai bagaimana sebenarnya para konsumen membuat keputusan dalam pembelian mereka, Thamrin dan Francis (2013:123).

Setiap pemasar wajib memahami situasi-situasi yang berpengaruh terhadap pembelian produk atau jasa yang ditawarkannya dan cara-cara terbaik melayani konsumen, suatu tantangan paling besar dihadapi oleh setiap perusahaan adalah saling berlomba-lomba mengetahui apa yang diinginkan konsumen, salah satunya menyediakan produk yang beraneka ragam karena adanya kecenderungan dalam diri konsumen yang menghendaki barang- barang yang beragam, berkualitas serta memiliki citra produk yang baik sehingga akan menciptakan keloyalan konsumen.

Saat ini terdapat banyak pusat perbelanjaan dan swalyan di Indonesia. Hal ini tentu menyebabkan persaingan karena konsumen menjadi banyak pilihan tempat-tempat berbelanja, sehingga para retailer tersebut harus bersaing dalam merebutkan konsumen serta

mempertahankan konsumen yang telah ada. Basmallah market adalah konsep swalayan yang menjual berbagai kelengkapan barang dan kebutuhan sehari- hari. Dengan berbagai jenis barang yang disediakan, Basmallah market mampu bersaing dengan mengandalkan motto "Tempat belanja yang baik".

Berdasarkan latar belakang diatas, maka penulis tertarik untuk memilih judul penelitian :

\section{ANALISIS PENGARUH FAKTOR KELENGKAPAN PRODUK, KUALITAS PRODUK DAN CITRA PRODUK TERHADAP LOYALITAS KONSUMEN DI BASMALAH MARKET KARANGGENENG LAMONGAN.}

\section{PERUMUSAN MASALAH}

Berdasarkan latar belakang diatas, maka dapat dirumuskan masalah sebagai berikut:

1. Apakah faktor kelengkapan produk,kualitas produk dan citra produk berpengaruh secara parsial terhadap loyalitas konsumen pada basmalah market karanggeneng lamongan?

2. Apakah faktor kelengkapan produk,kualitas produk, dan citra produk berpengaruh secara simultan terhadap loyalitas konsumen pada basmalah market karanggeneng lamongan?

3. Diantara faktor kelengkapan produk,kualitas produk, dan citra produk, mana yang lebih dominan berpengaruh terhadap loyalitas konsumen market basmalah karanggeneng lamongan?

\section{TUJUAN PENELITIAN}

1. Untuk mengetahui apakah faktor kelengakapan produk, kualitas produk, dan citra produk berpengaruh secara parsial terhadap loyalitas konsumen pada market basmalah karanggeneng lamongan.

2. Untuk mengetahui apakah faktor kelengakapan produk, kualitas produk, dan citra produk berpengaruh secara simultan terhadap loyalitas konsumen pada market basmalah karanggeneng lamongan.

3. Diantara faktor kelengkapan produk,kualitas produk, dan citra produk, mana yang lebih dominan berpengaruh terhadap loyalitas konsumen market basmalah karanggeneng lamongan. 


\section{Kelengkapan Produk}

Menurut Utami dalam Indri Hastuti Listyawati (2017:52) kelengkapan produk yang menyangkut kedalaman, luas, dan kualitas produk yang ditawarkan juga ketersediaan produk tersebut setiap saat ditoko. Penyediaan kelengkapan produk (product assortment) yang baik tidak hanya akan menarik minat tetapi dapat mempengaruhi keputusan konsumen untuk berbelanja.

Ketersediaan barang dalam suatu pasar swalayan meliputi variasi merk yang banyak, tipe dan ukuran kemasan barang yang dijual, macam-macam rasa dari suatu produk yang akan dibeli. Bagi sebuah pasar swalayan, kelengkapan barang dagangan merupakan faktor yang penting untuk menarik konsumen.

\section{Kualitas Produk}

Kualitas produk merupakan hal penting yang harus diusahakan oleh setiap perusahaan jika ingin yang dihasilkan dapat bersaing dipasar untuk memuaskan kebutuhan dan keinginan konsumen. Dewasa ini sebagian besar konsumen semakin kritis dalam mengkonsumsi suatu produk. Konsumen selalu ingin mendapatkan produk yang berkualitas sesuai dengan harga yang dibayar, meskipun ada sebagian masyarakat berpendapat bahwa, produk yang mahal adalah produk yang berkualitas, Buchari Alma (2013:159).

\section{Citra Produk}

Menurut Simamora dalam Made Suci Pratiwi (2014:03) Citra produk adalah satu cara untuk dapat membedakan suatu produk dengan produk lainnya. Citra produk juga diartikan sebagai sekumpulan asosiasi yang dipersepsikan konsumen terhadap suatu barang atau jasa. Oleh karena itu bagi perusahaan jasa memiliki citra yang baik menjadi sangat penting. Citra produk toko diartikan sebagai apa yang dipikirkan konsumen tentang toko, termasuk didalamnya presepsi dan sikap yang didasarkan pada sensasi dari rangsangan yang berkesan dengan toko yang diterima oleh benak konsumen melalui pengalaman pada toko tersebut.

\section{Loyalitas Konsumen}

Menurut Tjiptono dan Anastasia Diana (2015:210) Loyalitas konsumen adalah komitmen pelanggan terhadap suatu merek, toko atau pemasok berdasarkan sifat yang sangat positif dalam pembelian jangka panjang, dapat diartikan bahwa kesetiaan terhadap merek diperoleh karena adanya kombinasi adanya kepuasan dan keluhan. Sedangkan kepuasan pelanggan tersebut hadir dari seberapa besar kinerja perusahaan untuk menimbulkan kepuasan tersebut dengan meminimalkan keluhan sehingga diperoleh pembelian jangka panjang yang dilakukan oleh konsumen.

\section{METODE PENELITIAN Jenis Penelitian}

Jenis penelitian yang digunakan dalam penelitian ini adalah penelitian kuantitatif. yaitu metode penelitian yang berlandaskan pada filsafat positivisme. Pengumpulan data menggunakan instrumen penelitian. Analisis data bersifat kuantitatif atau statistik dengan tujuan untuk menguji hipotesis yang telah ditetapkan, Sugiyono (2014: 14)

Analisis data kuantitatif adalah analisis data berbentuk angka-angka dan analisis menggunakan statistic, Sugiyono (2014:7).

\section{Populasi dan Sampel}

Populasi dalam penelitian ini berjumlah 9000. Jumlah sampel ditentukan dengan rumus Slovin berjumlah 100 responden, yang dalam pengambilan anggota sampel menggunakan teknik simple random sampling. 


\section{Jenis Data}

Jenis data berdasarkan sumbernya ada 2 yaitu data primer dan data sekunder. Pada penelitian ini peneliti menggunakan data primer yaitu data dikumpulkan untuk riset dan data yang diperoleh langsung dari lapangan yaitu dari hasil kuisioner. Data ini diperoleh secara langsung dari sumber asli tanpa melalui perantara. Dan data sekunder yang dikumpulkan tidak hanya untuk keperluan suatu riset tertentu saja. Data ini dikumpulkan oleh pihak lain dan peneliti adalah pihak kedua yang menggunakan data tersebut. Data sekunder dalam penelitian ini meliputi data yang diperoleh dari internet mengenai fenomena-fenomena yang terjadi para bisnis ritel.

\section{Metode Analisis}

Metode analisis yang digunakan dalam penelitian ini adalah Uji validitas (Ghozali, 2013:52), Uji reliabilitas (Ghozali, 2013 : 47), Asumsi klasik (Ghozali, 2013:163), Analisis regresi linear berganda (Sugiyono, 2014 : 275), Koefisien determinasi (Ghozali, 2013:97), Uji t (Ghozali, 2013:98), Uji F (Ghozali, 2013:114).

\section{HASIL PENELITIAN DAN PEMBAHASAN}

\section{Hasil Penelitian Uji Validitas}

Berdasarkan hasil Uji Validitas instrument penelitian didapat bahwa seluruh butir pernyataan yang ada pada kuesioner mempunyai koefisien korelasi yang lebih besar dari r-table untuk $\mathrm{N}=100$ dengan nilai 0,196 dengan tingkat signifikansi uji dua arah 5\%.

\section{Uji Reliabilitas}

Dari Pengujian reliabilitas didapatkan hasil koefisien alpha pada semua variabel bebas kelengkapan produk 0,739, kualitas produk 0,832, Citra produk 0,648 dan variabel terikat loyalitas konsumen sebesar 0,675 lebih besar dari standart reliabilitas 0,60 dengan tingkat signifikansi $a=5 \%$ sehingga dapat disumpulkan bahwa instrumen dalam variabel bebas dan variabel terikat adalah reliabel.

\section{Uji Asumsi Klasik}

Hasil uji normalitas, multikolinearitas dan uji heteroskedastisitas menunjukkan bahwa model regresi telah memenuhi asumsi klasik, sehingga dapat dilakukan analisis regresi linear berganda.

\section{Analisis Regresi Linear Berganda}

Pengujian ini dilakukan untuk mengukur seberapa besar pengaruh dari variabel independen (kelengkapan produk, Kualitas produk dan Citra produk) terhadap variabel dependen (Loyalitas Konsumen). Perhitungan statistik dalam analisis regresi linear berganda yang digunakan dalam penelitian ini adalah menggunakan program SPSS versi 23. Berdasarkan hasil analisis regresi linear berganda diperoleh hasil sebagai berikut:

Tabel I.

Hasil Pengujian Regresi Linear Berganda

Coefficients $^{\mathrm{a}}$

\begin{tabular}{|c|c|c|c|c|c|c|c|}
\hline \multirow[b]{2}{*}{ Model } & \multicolumn{2}{|c|}{$\begin{array}{l}\text { Unstandardized } \\
\text { Coefficients }\end{array}$} & \multirow{2}{*}{$\begin{array}{c}\text { Standardized } \\
\text { Coefficients } \\
\text { Beta }\end{array}$} & \multirow[b]{2}{*}{$\mathrm{T}$} & \multirow[b]{2}{*}{ Sig. } & \multicolumn{2}{|c|}{ Collinearity Statistics } \\
\hline & B & $\begin{array}{l}\text { Std. } \\
\text { Error }\end{array}$ & & & & Tolerance & VIF \\
\hline $\begin{array}{l}\text { (Constant) } \\
\mathrm{X} 1\end{array}$ & $\begin{array}{l}4.374 \\
.187\end{array}$ & $\begin{array}{l}.533 \\
.058\end{array}$ & .182 & $\begin{array}{l}8.200 \\
3.244\end{array}$ & .000 & .841 & 1.189 \\
\hline
\end{tabular}




\begin{tabular}{|l|l|l|l|l|l|l|l|}
$\mathrm{X} 2$ & .308 & .047 & .354 & 6.615 & .000 & .919 & 1.088 \\
$\mathrm{X} 3$ & .341 & .030 & .621 & 11.217 & .000 & .861 & 1.162 \\
\hline
\end{tabular}

a. Dependent Variable: Y

Sumber: Data primer yang diolah menggunakan SPSS versi 23 (2018)

Berdasarkan hasil perhitungan di atas diperoleh persamaan regresi linear berganda dari variabel kelengkapan produk (X1), Kualitas Produk (X2), Citra Produk (X3) terhadap Loyalitas Konsumen (Y) adalah sebagai berikut:

$\mathrm{Y}=4.374+0,187 \mathrm{X} 1+0,308 \mathrm{X} 2+0,341 \mathrm{X} 3+\mathrm{e}$

Persamaan regresi dapat dijelaskan seperti dibawah ini:

$a=4,374$ merupakan constanta yang berarti bahwa variabel bebas dalam penelitian ( kelengkapan produk, kualitas produk dan citra produk) pengaruhnya $=0$, maka hasil dari loyalitas konsumen adalah 4,374.

$\mathrm{b}_{1}=0,187$ artinya jika variabel kelengkapan produk mengalami kenaikan $1 \%$ maka loyalitas konsumen akan mengalami peningkatan sebesar 0,187.

$\mathrm{b}_{2}=0,308$ artinya jika variabel kualitas produk mengalami kenaikan 1\% maka loyalitas konsumen akan mengalami peningkatan sebesar 0,308 .

$\mathrm{b}_{3}=0,341$ artinya jika variabel Citra produk mengalami kenaikan 1\% maka loyalitas konsumen akan mengalami peningkatan sebesat 0,341 .

\section{Analisis Koefisien Determinasi}

. Dari perhitungan Koefisien Determinasi $\left(\mathrm{R}^{2}\right)$ yang diperoleh dari hasil $\mathrm{R}$ Square sebesar 0,747. Hal ini menunjukkan bahwa 74,7\% loyalitas konsumen Basmallah Market

Karanggeneng Lamongan dapat dijelaskan oleh variabel independen yang terdiri dari Kelengkapan Produk, Kualitas Produk, dan Citra produk sedangkan sisanya yaitu 25,3\% loyalitas konsumen Basmallah Market Karanggeneng Lamongan dipengaruhi oleh variabelvariabel lain yang tidak diteliti dalam penelitian ini.

\section{Uji t (Uji Parsial)}

Uji t digunakan untuk menguji apakah masing-masing variabel bebas berpengaruh dan signifikan terhadap loyalitas konsumen pada Basmallah Market Karanggeneng Lamongan dengan cara membandingkan thitung dan t tabel dengan tingkat kepercayaan sebesar $\alpha=0,05$ sehingga diperoleh hasil perhitungan SPSS.

Coefficients $^{\mathrm{a}}$

Tabel II. Uji t parsial

\begin{tabular}{|c|c|c|c|c|c|}
\hline \multirow[b]{2}{*}{ Model } & \multicolumn{2}{|c|}{$\begin{array}{l}\text { Unstandardized } \\
\text { Coefficients }\end{array}$} & \multirow{2}{*}{$\begin{array}{c}\begin{array}{l}\text { Standardiz ed } \\
\text { Coefficients }\end{array} \\
\text { Beta }\end{array}$} & \multirow[b]{2}{*}{$\mathrm{T}$} & \multirow[b]{2}{*}{ Sig. } \\
\hline & B & Std. Error & & & \\
\hline (Constant) & 4.374 & .533 & & 8.200 & .000 \\
\hline $\mathrm{X} 1$ & .187 & .058 & .182 & 3.244 & .002 \\
\hline $\mathrm{X} 2$ & .308 & .047 & .354 & 6.615 & .000 \\
\hline X3 & .341 & .030 & .621 & 11.217 & .000 \\
\hline
\end{tabular}

a. Dependent Variable: Y

Sumber: Data primer yang diolah menggunakan SPSS 23 (2018)

Berdasarkan Tabel. II diatas dapat dijelaskan bahwa hasil signifikan uji statistik t untuk masingmasing variabel adalah sebagai berikut:

1. Kelengkapan Produk $\left(\mathrm{X}_{1}\right)$, berdasarkan hasil uji statistik $t$, didapatkan hasil $t_{\text {hitung }}$ untuk variabel Kelengkapan Produk $\left(\mathrm{X}_{1}\right)$ sebesar 
3.244 dengan taraf nilai signifikan $a=0,05$ maka $t_{a} /{ }_{2}=t_{0,025} ; d f=n-k-1=100-3-1=96$, maka diperoleh $t_{\text {tabel }}=1,985$. Hasil analisis data diperoleh nilai $t_{\text {hitung }}=3.244$ dan nilai sig $=$ 0,002 , maka $t_{\text {hitung }}>t_{\text {tabel }}(3.244>1985)$ dan sig $<0,05(0,002<0,05)$ maka $_{0}$ ditolak dan $\mathrm{H}_{\mathrm{a}}$ diterima, sehingga dapat diartikan bahwa untuk variabel $\left(\mathrm{X}_{1}\right)$ secara parsial memiliki pengaruh yang signifikan terhadap variabel $\mathrm{Y}$.

2. Kualitas Produk $\left(\mathrm{X}_{2}\right)$, berdasarkan hasil uji statistik $t$, didapatkan hasil $t_{\text {hitung }}$ untuk variabel Kualitas Produk $\left(\mathrm{X}_{2}\right)$ sebesar 6.615 dengan taraf nilai signifikan $\mathrm{a}=0,05$ maka $\mathrm{t}_{\mathrm{a}} / \mathrm{2}_{2}=\mathrm{t}_{0,025}$; $\mathrm{df}$ $=\mathrm{n}-\mathrm{k}-1=100-3-1=96$, maka diperoleh $\mathrm{t}_{\text {tabel }}=1,985$. Hasil analisis data diperoleh nilai $\mathrm{t}_{\text {hitung }}=$ 6.615 dan nilai sig $=0,000$, maka $t_{\text {hitung }}>t_{\text {tabel }}(6.615>1985)$ dan sig $<0,05(0,000$

$<0,05)$ maka $\mathrm{H}_{0}$ ditolak dan $\mathrm{H}_{a}$ diterima, sehingga dapat diartikan bahwa untuk variabel $\left(\mathrm{X}_{2}\right)$ secara parsial memiliki pengaruh yang signifikan terhadap variabel $\mathrm{Y}$.

3. Citra Produk $\left(\mathrm{X}_{3}\right)$, berdasarkan hasil uji statistik $t$, didapatkan hasil $t_{\text {hitung }}$ untuk variabel Citra Produk $\left(\mathrm{X}_{3}\right)$ sebesar 11.217 dengan taraf nilai signifikan $\mathrm{a}=0,05$ maka $\mathrm{t}_{\mathrm{a}} /{ }_{2}=\mathrm{t}_{0,025}$ ; $\mathrm{df}=\mathrm{n}-\mathrm{k}-1=100-3-1=96$, maka diperoleh $\mathrm{t}_{\text {tabel }}=1,985$. Hasil analisis data diperoleh nilai $t_{\text {hitung }}=11.217$ dan nilai sig $=0,000$, maka thitung $>t_{\text {tabel }}(11.217>1985)$ dan sig $<0,05 \quad(0,000$ $<0,05)$ maka $\mathrm{H}_{0}$ ditolak dan $\mathrm{H}_{\mathrm{a}}$ diterima, sehingga dapat diartikan bahwa untuk variabel $\left(\mathrm{X}_{3}\right)$ secara parsial memiliki pengaruh yang signifikan terhadap variabel $\mathrm{Y}$.

\section{Uji F ( Uji Serentak)}

Uji F digunakan untuk menguji apakan perubahan variabel independen (kelengkapan produk, Kualitas produk dan Citra produk) berpengaruh signifikan terhadap variabel dependen ( loyalitas konsumen ) pada Basmalah market karanggeneng lamongan, yakni dengan membandingkan $\mathrm{F}$ hitung dengan $\mathrm{F}$ tabel dengan tingkat kepercayaan sebesar 95\% $(\mathrm{a}=0,05)$. Hasil uji $\mathrm{F}$ dari perhitungan SPSS sebagai berikut:

Tabel III.

Uji Statistik F ( Pengujian Hipotesis Secara Simultan)

ANOVA $^{\mathrm{a}}$

\begin{tabular}{|l|c|l|l|l|l|}
\hline Model & $\begin{array}{c}\text { Sum of } \\
\text { Squares }\end{array}$ & df & Mean Square & F & Sig. \\
\hline Regression & 63.476 & 3 & 21.159 & 94.545 & $.000^{\text {b }}$ \\
Residual & 21.484 & 96 & .224 & & \\
Total & 84.960 & 99 & & & \\
\hline
\end{tabular}

a. Dependent Variable: Y

b. Predictors: (Constant), X3, X2, X1

Sumber : Data Primer yang diolah menggunakan SPSS versi 23 (2018)

Berdasarkan hasil uji statistik $\mathrm{F}$ pada Tabel 5.15 diatas menunjukkan bahwa nilai $\mathrm{F}_{\text {hitung }}$ sebesar 94.545 dengan tingkat sig. sebesar 0,000. Pada taraf nilai signifikan $a=0,05$ dengan df1 $=\mathrm{k}-1=4-1=3 ; \mathrm{df} 2=\mathrm{n}-\mathrm{k}-1=100-3-1=96$, maka nilai $\mathrm{F}_{\text {tabel }}=2,70$. Hasil analisis data diperoleh nilai $\mathrm{F}_{\text {hitung }}=94.545$ dan nilai sig. $=0,000$, maka $\mathrm{F}_{\text {hitung }}>\mathrm{F}_{\text {tabel }}$ ( $94.545>2,70)$ dan sig. $<0,05(0,00<0,05)$ maka $\mathrm{H}_{0}$ ditolak $\mathrm{H}_{\mathrm{a}}$ diterima. Dengan Demikian dapat diartikan bahwa hipotesis yang menyatakan secara simultan variabel independen yang terdiri dari Kelengkapan produk, Kualitas Produk, dan Citra Produk berpengaruh signifikan terhadap variable dependen Loyalitas Konsumen Basmallah Market Karanggeneng Lamongan dapat diterima atau terbukti kebenarannya.

\section{PENUTUP}

Simpulan

50 Profit : Jurnal Kajian Ekonomi dan Perbankan 
Berdasarkan analisis dan pembahasan yang sudah dijelaskan pada bab sebelumnya, maka dapat diambil kesimpulan sebagai berikut:

1. Dari ketiga variabel yaitu: Kelengkapan Produk, Kualitas Produk dan Citra Produk berpengaruh secara parsial memiliki pengaruh signifikan terhadap loyalitas konsumen Basmallah Market Karanggeneng Lamongan.

2. Dari hasil pengujian secara simultan diperoleh hasil analisis data nilai $\mathrm{F}_{\text {hitung }}=94.545$ dan nilai sig $=0,000$, maka Fhitung $>F_{\text {tabel }}(94.545>2,70)$ dan sig. $<0,05(0,000<0,05)$. Dari ketiga variabel yang terdiri dari: Kelengkapan Produk, Kualitas Produk dan Citra Produk berpengaruh signifikan terhadap loyalitas konsumen Basmallah Market Karanggeneng Lamongan.

3. Berdasarkan hasil analisis regresi $\mathrm{Y}=4.374+0,187 \mathrm{X}_{1}+0,308 \mathrm{X}_{2}+0,341 \mathrm{X}_{3}$ variabel yang memiliki pengaruh lebih dominan terhadap loyalitas konsumen adalah variabel Citra Produk $\left(\mathrm{X}_{3}\right)$ karenamempunyai nilai koefisien (Beta) sebesar 0,621.

\section{SARAN}

Berdasarkan hasil pembahasan dan kesimpulan yang sudah dijelaskan sebelumnya, adapun saran yang dapat diberikan, diantaranya adalah:

1. Dengan diketahui citra produk merupakan faktor yang paling dominan berpengaruh dalam peningkatan loyalitas konsumen Basmallah Market Karanggeneng Lamongan, maka berdasarkan hasil tersebut hendaklah pihak pengelola toko Basmallah Market Karanggeneng Lamongan harus benar-benar mengetahui citra produk yang akan dijual pada konsumen.

2. Basmallah Market Karanggeneng Lamongan dalam melakukan kegiatan harapanya memberikan perhatian yang lebih besar untuk meningkatakan kelengkapan produk dan kualitas produk sehingga loyalitas konsumen atau pelanggan dapat tercapai.

3. Penelitian selanjutnya sebaiknya mengembangkan variabel-variabel yang diteliti, sebab tidak menutup kemungkinan bahwa dengan penelitian yang mencakup lebih banyak variabel akan dapat menghasilkan kesimpulan yang lebih baik. 


\section{DAFTAR PUSTAKA}

Abdullah, Thamrin dan Francis Tantri, 2013. Manajemen Pemasaran,Edisi pertama, Cetakan ke-2, Rajawali Pers, Jakarta.

Alma, Buchari 2013, Manajemen Pemasaran dan Pemasaran Jasa. Edisi Revisi, Cetakan 10. Bandung, Alfabeta

Burhanudin AL- Ghazali, 2016. Pengaruh Harga Produk \& Kualitas Produk Terbadap Keputusan Pembelian UD. Lupi Bakry Dusun Lopang Kec. Kembang Bahu

Ghozali, Imam. 2013. Aplikasi Analisis Multivariate Dengan Program IBM SPSS 21 Update PLS Regresi. Semarang, Universitas diponegoro

Listyawati Hastuti Indri, Vol. 4 NO. 9, 2017. Pengarub Lokasi, Kelengkapan Produk, Kualitas Produk. dan Promosi Terbadap Keputusan Beli Konsumen

Pratiwi Suci Made, Vol 2. 2014. Pengaruh Citra Perusahaan, Citra Produk Dan Citra Pemakai Terhadap Keputusan Pembelian Produk Foremost Pada Distro Ruby Sobo Di Singaraja.

Sugiyono,2014: Metode Penelitian Kuantitatif Kualitatif Dan R \& D, Penerbit, Alfabeta, Bandung

Sugiyono,2016: Metode Penelitian Kuantitatif Kualitatif Dan R \&D, Penerbit, Alfabeta Bandung

Tjiptono, Fandy. 2015. Pelanggan Puas Tak Cukup. Penerbit Andi Publisher Yogyakart.

Widodo Tri, vol. 9 No. 17. 2016. Pengaruh Kelengkapan Produk Dan Kualitas Pelayanan Terbadap ke 